\title{
Effects of acute prolactin manipulation on sexual drive and function in males
}

\author{
T H C Krüger, P Haake, J Haverkamp, M Krämer, M S Exton, \\ B Saller ${ }^{1}$, N Leygraf $^{2}$, U Hartmann ${ }^{3}$ and M Schedlowski \\ Department of Medical Psychology, University of Essen, Hufelandstrasse 55, 45122 Essen, Germany \\ ${ }^{1}$ Division of Endocrinology, Department of Medicine, University of Essen, 45122 Essen, Germany \\ ${ }^{2}$ Department of Forensic Psychiatry, University of Essen, 45122 Essen, Germany \\ ${ }^{3}$ Department of Clinical Psychiatry, Hanover Medical School, 30625 Hanover, Germany \\ (Requests for offprints should be addressed to T H C Krüger; Email: tillmann.krueger@web.de)
}

\begin{abstract}
The neuroendocrine response to sexual activity in humans is characterized by a pronounced orgasm-dependent increase of plasma levels of prolactin. In contrast to the well-known inhibitory effects of chronic hyperprolactinemia on sexual drive and function, the impact of acute prolactin alterations on human sexual physiology is unknown. Therefore, this study was designed to investigate the effects of acute manipulation of plasma prolactin on sexual behavior.

Ten healthy males participated in a single-blind, placebo-controlled, balanced cross-over design. Prolactin levels were pharmacologically increased to high levels (protirelin, $50 \mu \mathrm{g}$ i.v.) or reduced to low physiological concentrations (cabergoline, $0.5 \mathrm{mg}$ p.o.). Sexual arousal and orgasm were then induced by an erotic film and masturbation. In addition to continuous neuroendocrine and cardiovascular recordings, the quality and intensity of the acute sexual drive, arousal, orgasm and refractory period were assessed by extensive psychometric measures.
\end{abstract}

Administration of cabergoline decreased prolactin levels and significantly enhanced all parameters of sexual drive $(P<0 \cdot 05)$, function $(P<0 \cdot 01)$ and positive perception of the refractory period $(P<0 \cdot 01)$. Administration of protirelin increased prolactin concentrations and produced small, but not significant reductions of sexual parameters. The sexual effects observed from cabergoline were completely abrogated by coadministration of protirelin.

Although different pharmacological sites of action of prolactin-altering drugs have to be considered, these data demonstrate that acute changes in prolactin plasma levels may be one factor modulating sexual drive and function. Therefore, besides a neuroendocrine reproductive reflex, a post-orgasmic prolactin increase may represent one factor modulating central nervous system centers controlling sexual drive and behavior. These findings may offer a new pharmacological approach for the treatment of sexual disorders.

Journal of Endocrinology (2003) 179, 357-365

\section{Introduction}

The characterization and relevance of the neuroendocrine response to human sexual activity has received little scientific attention. Previously, large methodological differences in inducing sexual activity (viewing of stimulating films, imagery of fantasies, masturbation, coitus), collecting blood samples (blood sampling at single discrete time points) and the experimental setting (examination cabin, investigator entering the room) have resulted in heterogeneous data regarding the acute neuroendocrine response pattern to sexual arousal, thereby ensuring that this phenomenon is poorly understood (Meston \& Frolich 2000, Krüger et al. 2002).

Therefore, we developed a model to record continuously the neuroendocrine response to various forms of sexual stimulation, including films, masturbation and coitus in both men and women. This series of studies have consistently demonstrated that plasma prolactin concentrations are substantially increased following orgasm in both men and women, but unchanged following sexual arousal without orgasm (Krüger et al. 1998, 2003, M S Exton et al. 1999, 2001a, N G Exton et al. 2000). Furthermore, elevations of prolactin following orgasm remain increased over the experimental session, and remain raised $60 \mathrm{~min}$ following sexual arousal.

There is clinical and experimental evidence suggesting that the prolactin response to orgasm may not only affect reproductive organs (Outhit et al. 1993, Bole-Feysot et al. 1998, Goffin et al. 1999), but also play a role in the control of acute sexual arousal following orgasm. Supporting this position, chronic elevations of prolactin 
(hyperprolactinemia), induced by prolactin-secreting tumors or as a side effect of typical neuroleptics, produce pronounced reductions of sexual drive and gonadal functions in animals (Doherty et al. 1986) and humans (Yazigi et al. 1997, Hummer et al. 1999, Knegtering et al. 2003). Importantly, these effects are reversed upon pharmacological or surgical restoration of normal prolactin levels (Verhelst et al. 1999). We therefore proposed a theoretical model suggesting that orgasm-induced prolactin release may modify dopaminergic systems within the central nervous system (CNS) that are responsible for controlling sexual drive and refractoriness (Krüger et al. 2002). Besides a short-loop feedback to tuberoinfundibular dopaminergic neurons regulating pituitary prolactin release (DeMaria et al. 1999), peripheral prolactin may be able to affect dopaminergic neurons in the nigrostriatal and mesolimbocortical system and the medial preoptic area. Animal studies have demonstrated that these sites are responsible for the regulation of genital responses, appetitive behavior and motor activity (Hull et al. 1999, Krüger et al. 2002). Although prolactin is not able to pass the blood-brain barrier due to its size (199 amino acid peptide), it may reach these areas via the blood-CSF barrier and the circumventricular organs (Gangong 2000, Sobrinho 1993).

To elucidate the function of orgasm-induced prolactin secretion in humans, we here analyzed the effects of acute pharmacological manipulations of prolactin plasma levels on sexual arousal, orgasm and the refractory period in healthy young males, utilizing a single-blind, placebocontrolled cross-over study design. Using the established experimental paradigm (Krüger et al. 2002), prolactin levels were altered to either high or low physiological concentrations. Additionally, immediately after the $60 \mathrm{~min}$ session a second orgasm was induced by a pornographic film. This allowed examination of the subjects' refractory period and the ability to reinitiate sexual activity. In addition to measurement of cardiovascular and neuroendocrine parameters, variables of sexual drive and function were evaluated using a questionnaire that has been specifically developed for the assessment of acute sexual experiences in a laboratory setting.

\section{Materials and Methods}

\section{Subjects}

Ten healthy males (mean age $25 \cdot 9 \pm 2.5$ years, age range 22-31 years) participated in this study after providing written informed consent. Participants were recruited by advertisement at the University of Essen. The investigation was conducted in accordance with the guidelines proposed in The Declaration of Helsinki and was approved by the Ethics Committee for investigations involving human subjects at the University Clinics of Essen. Participants completed a general medical/health questionnaire to exclude individuals taking medication, abusing drugs/alcohol, exhibiting endocrinological or psychological disorders or fulfilling any contraindication for the administration of protirelin or cabergoline. Additionally, a questionnaire for the evaluation of sexual problems/dysfunctions in males was employed. Furthermore, subjects were screened for psychogenic erectile dysfunction by questionnaire of the dual control model of male sexual response (Bancroft \& Janssen 2000). Subjects did not show any significant differences in the specific subscales (sexual inhibitory and excitatory scale) in comparison with a normative sample of healthy males.

Subjects underwent a semi-structured interview and a physical examination by a research physician. All participants were sexually active and reported an exclusively heterosexual orientation and a relaxed attitude towards masturbation and erotic films. Subjects reported an average refractory period of $18 \cdot 43 \pm 2 \cdot 30 \mathrm{~min}$.

\section{Design and procedure}

The investigation was performed using a single-blind, placebo-controlled, balanced cross-over design. A repeated measures design was used so that each subject participated in four experimental sessions in a different order, experiencing the conditions of: lowered prolactin, elevated prolactin, blunted prolactin (coadministration of both drugs), and unaltered prolactin (placebo); further, subjects participated in a control session where a documentary film was shown. In total, each subject participated in five examinations. All sessions took place at $1600 \mathrm{~h}$ (Fig. 1). A one week interval separated each session, with the exception of the low-prolactin session, which was followed by an interval of one month due to long-lasting effects of the prolactin-lowering drug cabergoline in few persons (Andreotti et al. 1995).

Experiments were conducted in a separate soundattenuated room equipped with a reclining armchair, a color television and a video cassette player. All leads, including the blood line, passed through the wall into the adjacent room where the cardiovascular data and blood samples were collected, allowing subjects to be completely isolated throughout the entire experiment. At the beginning of the experiments subjects positioned themselves in the armchair in front of the screen. The cardiovascular monitor was then engaged $20 \mathrm{~min}$ prior to the film and a steady baseline reading was obtained before the cannula was inserted (15 min before the film). Depending on the condition, prolactin-altering drugs or $\mathrm{NaCl}$ were then injected i.v. Continuous blood sampling was initiated immediately before the beginning of the film, with the samples divided into nine $10 \mathrm{~min}$ intervals (Krüger et al. 1998, M S Exton et al. 1999, 2001a,b, N G Exton 2000). Specifically, sample 0 represented a basal value before i.v. drug administration. Samples 1 and 2 represented basal value during the neutral stimulus, sample 3 represented 
Documentary

Control-session

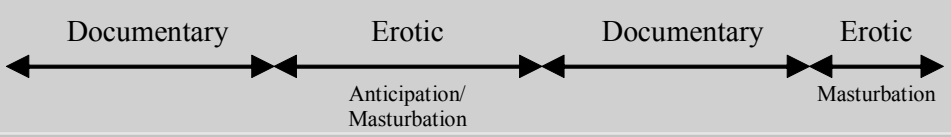

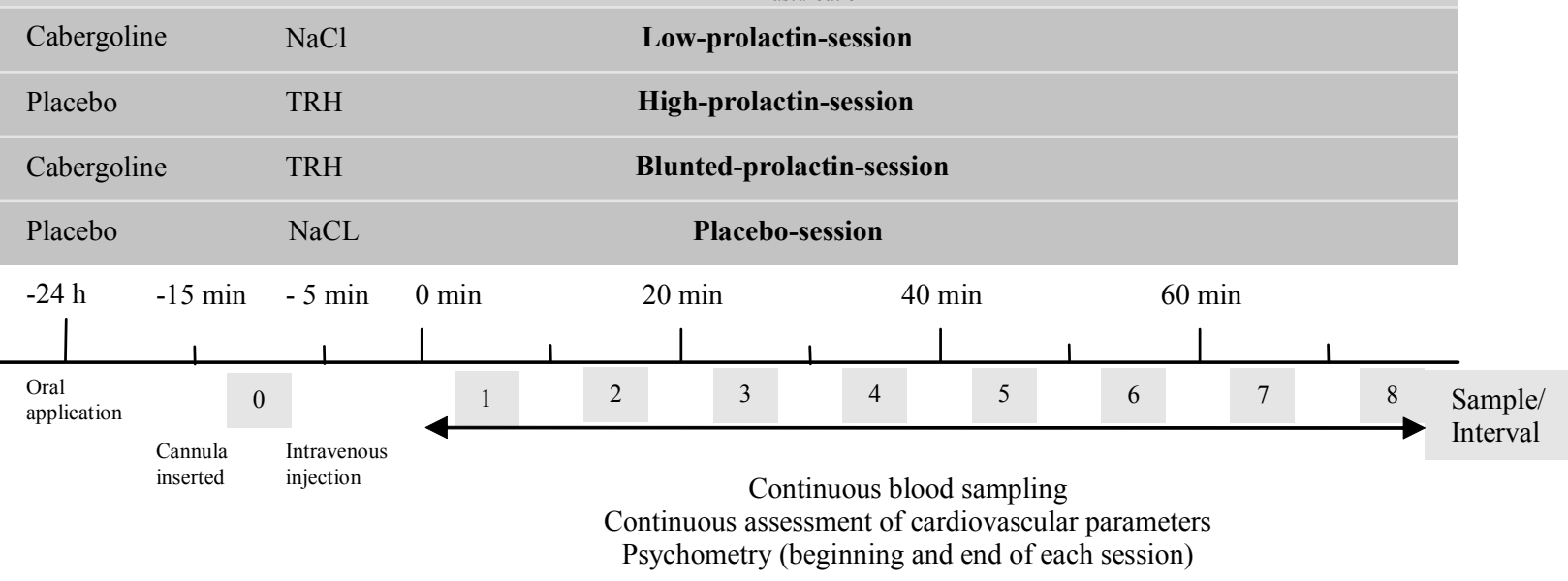

Figure 1 Experimental paradigm for investigating the effects of acute prolactin manipulation on sexual arousal and orgasm in a laboratory setting. Plasma sample 0 represented a basal value before i.v. drug administration. Samples 1 and 2 represented basal values during the neutral stimulus, sample 3 represented the response to film-induced sexual arousal, sample 4 demonstrated the response to orgasm, the next two samples ( 5 and 6 ) displayed the recovery phase, sample 7 again demonstrated sexual arousal and orgasm/reinitiation of sexual activity, with sample 8 representing another post-orgasmic phase.

the response to film-induced sexual arousal, sample 4 demonstrated the response to orgasm, the next two samples (5 and 6) displayed the recovery phase, sample 7 again demonstrated sexual arousal and orgasm/reinitiation of sexual activity, with sample 8 representing another post-orgasmic phase.

In the experimental sessions a documentary film was observed for $20 \mathrm{~min}$, followed by $20 \mathrm{~min}$ of a pornographic film, and a further $20 \mathrm{~min}$ documentary. Following $10 \mathrm{~min}$ of the pornographic film, subjects were asked to masturbate until orgasm. Finally, another $10 \mathrm{~min}$ of pornographic film were presented for the examination of refractory period and reinitiation of sexual arousal and orgasm. Immediately after the session, subjects completed the psychometric scales.

Subjects also participated in a control session, where a documentary film was shown for $70 \mathrm{~min}$. Together, every subject participated in five different sessions in a counterbalanced order. Different documentary and pornographic sequences were employed throughout the sessions so as to avoid habituation effects. The documentary consisted of travel stories and natural science, whereas the erotic sequences consisted of heterosexual couples stimulating each other and having intercourse. All visual stimulation had been established in previous studies (Krüger et al. 1998, M S Exton et al. 1999, 2001a,b, N G Exton 2000).

\section{Pharmacological prolactin manipulation}

Due to ethical and practical difficulties, the use of synthetic or purified prolactin or prolactin antagonists to alter plasma prolactin has not been established in humans. Nevertheless, manipulation of prolactin release may be conducted at the hypothalamus-pituitary level, where the regulation of prolactin mainly remains under tonic inhibitory dopaminergic control (Macleod \& Lehmeyer 1974).

Prolactin levels were lowered by oral administration of $0.5 \mathrm{mg}$ of the D2-receptor agonist cabergoline (Dostinex, Pharmacia \& Upjohn), which is well-tolerated without significant side effects in this dosage (Andreotti et al. 1995). Effects on other, nonprolactinergic endocrine variables have not been reported. Cabergoline was given the 
evening before the examination, thus ensuring decreased prolactin levels throughout the session (Fig. 1).

Prolactin was increased by i.v. injection of $50 \mu \mathrm{g}$ protirelin (Relefact TRH 200/400, Hoechst Marion Roussell), which is one-eighth to a quarter dose of that used diagnostically in the thyrotropin-releasing hormone $(\mathrm{TRH})$ test and well-tolerated in this dosage. Protirelin was given at the beginning of the experiment, thus producing the desired prolactin increase during the period of sexual arousal and orgasm (Garbutt et al. 1994, Horita 1998). Consecutive increases of thyroxine and triiodothyronine occur with a certain latency.

In another condition participants received a combination of $50 \mu \mathrm{g}$ protirelin and $0.5 \mathrm{mg}$ cabergoline. The administration of both drugs was done to allow detection of the prolactin-independent effects of cabergoline and protirelin.

The time kinetics of the effects of protirelin and cabergoline on plasma prolactin were examined in a preliminary study and controlled throughout the experimental sessions. The dosages of both substances were adjusted with the aim of achieving prolactin levels that represented either low physiological concentrations or levels mirroring approximately those produced by orgasm (Krüger et al. 1998, M S Exton et al. 1999, 2001a). The whole examination was placebo-controlled.

Side effects of drug administration on nonsexual parameters were screened by a specific questionnaire. There were no significant differences between the verum and placebo conditions.

\section{Measures}

Cardiovascular measures The cardiovascular parameters heart rate and systolic and diastolic blood pressure were monitored continuously via a finger cuff connected to a blood pressure monitor (Finapres; Ohmeda, Louisville, CO, USA) in the adjoining room. Cardiovascular activity was recorded every $30 \mathrm{~s}$, and the heart rate and blood pressure values were averaged over $10 \mathrm{~min}$ intervals and analyzed in parallel with the $10 \mathrm{~min}$ interval blood samples (Krüger et al. 1998).

Endocrine measures For continuous blood sampling an i.v. cannula (Kliniject, $18 \mathrm{G}$, Klinika Medical $\mathrm{GmbH}$, Usingen, Germany) was inserted into a forearm vein of the nondominant arm and connected to a $1.25 \mathrm{~m}$ heparinized silicon tube (inner diameter $2.0 \mathrm{~mm}$; Reichelt Chemie, Heidelberg, Germany). The silicon tubing passed through the wall into the adjoining room and was driven by a peristaltic pump (Fresenius, Homburg, Germany). Blood flow was adjusted to $2 \mathrm{ml} / \mathrm{min}$, collected into EDTA tubes (Sarstedt, Nümbrecht, Germany) and divided into 10 min intervals. The dead space of the blood collection system was about $4 \mathrm{ml}$ and the collection of each sample was delayed by $2 \mathrm{~min}$. Blood was stored on ice until the samples were centrifuged at $4{ }^{\circ} \mathrm{C}$ and stored at $-70{ }^{\circ} \mathrm{C}$ until assayed (Krüger et al. 1998, M S Exton et al. 1999, 2001a,b, N G Exton 2000).

All samples of each participant for a particular hormone were assayed in duplicate within the same assay. Catecholamine plasma levels were measured by HPLC (Ehrenreich et al. 1997, Smedes et al. 1982). The intraand interassay variability for noradrenaline were 6.2 and $8 \cdot 0 \%$ respectively, and $4 \cdot 0$ and $5 \cdot 1 \%$ respectively for adrenaline. All other hormones like thyrotropin (TSH), prolactin, follicle-stimulating hormone (FSH), luteinizing hormone $(\mathrm{LH})$, testosterone and cortisol were detected by the Automated Chemiluminescence-ImmunoassaySystem 180 (ACS: Centaur; Chiron Diagnostics, Leverkusen, Germany). The intra- and interassay coefficients of variance were 3.3 and $3.5 \%$ for TSH, 2.5 and $3.6 \%$ for prolactin, 2.8 and $4.6 \%$ for $\mathrm{FSH}, 4.7$ and $6.3 \%$ for LH, 5.6 and $6 \cdot 6 \%$ for testosterone and 4.5 and $6 \cdot 4 \%$ for cortisol respectively.

Psychometric measures To the best of our knowledge there is no standardized questionnaire for the evaluation of acute sexual experience in an experimental situation. Therefore, we designed an acute sexual experience scale (ASES), containing six subscales with 52 items. The questionnaire evaluates different characteristics of appetitive, consummatory and refractory sexual behavior in males. One part of the questionnaire consists of control items, for evaluating parameters such as the occurrence of orgasm and ejaculation latency. However, the investigators also registered this by online observation of cardiovascular measurements (rapid decrease of heart rate and blood pressure immediately after orgasm), and by subject registration of the start and end of masturbation via intercom. Another part of the questionnaire consists of self-reporting ratings of sexual functioning using visual analog rating scales (0-100, from 'not at all' to 'extremely'). The scales examined sexual functioning both in absolute values and as compared with normally experienced sexuality in a real life situation such as masturbation and sexual intercourse. In detail, the first subscale, 'appetitive phase', assessed features of sexual arousability, lust and desire during the first part of the pornographic video presentation where subjects remained passive (e.g. 'Please estimate the intensity of sexual arousal while watching the pornographic video'). The second subscale 'consummatory phase' evaluated the quality, intensity and duration of orgasm and sexual release associated with orgasm during the second part of the pornographic sequence where subjects were asked to masturbate (e.g. 'Please estimate the intensity of your orgasm'). The third subscale 'refractory phase' evaluated both negative aspects of refractoriness like tiredness, recovery and soberness (negative scale, e.g. 'Please estimate the grade of tiredness you perceived after orgasm') and positive aspects like sexual release and relaxation 
(positive scale, e.g. 'Please estimate the feeling of being far away after orgasm'). The fifth and sixth scale again assessed the appetitive and consummatory phase during the reinitiation of sexual arousal and orgasm.

\section{Statistical analyses}

Cardiovascular and endocrine data from all subjects were analyzed by a two-factor repeated measures (condition $\times$ time) ANOVA. If not otherwise stated we report the condition $\times$ time interaction effect. Planned, paired-samples $t$-tests were conducted on each scale of the questionnaire for ASES between the cabergoline, protirelin, cabergoline plus protirelin and placebo conditions. An $\alpha$ of 0.05 was considered statistically significant for all analyses.

\section{Results}

\section{Cardiovascular measures}

In parallel to increased subjective sexual arousal during the pornographic sequences, participants revealed a transient increase in heart rate $(\mathrm{F}[6,54]=6 \cdot 07, P<0 \cdot 001)$, systolic $(\mathrm{F}[6,54]=9 \cdot 38, P<0 \cdot 001)$ and diastolic $(\mathrm{F}[6,54]=8 \cdot 87$, $P<0.001$ ) blood pressure during sexual arousal and orgasm (interval three, four and seven), with an immediate decline after orgasm to baseline levels. No significant differences between the experimental conditions were found (data not shown).

\section{Endocrine measures}

In the placebo condition, prolactin plasma levels increased an average of $50 \%$ during orgasm and remained elevated thereafter $(F[8,72]=6 \cdot 56, P<0 \cdot 001)$. A further prolactin increase was observed during the second orgasm in the seventh interval. Prolactin plasma concentrations and all other endocrine variables remained unchanged during the documentary film (Fig. 2a).

The group receiving cabergoline showed decreased prolactin concentrations throughout the session, with plasma levels of approximately $2 \cdot 5 \mathrm{ng} / \mathrm{ml}(\mathrm{F}[8,72]=6 \cdot 01$, $P<0 \cdot 001$ ) (Fig. 2b).

The administration of $50 \mu \mathrm{g}$ protirelin induced an immediate increase of prolactin plasma levels, achieving initial concentrations of $28 \mathrm{ng} / \mathrm{ml}$ on average, declining consistently towards slight supraphysiological levels during sexual arousal and orgasm $(20.5 \mathrm{ng} / \mathrm{ml})$, and decreased further towards upper physiological levels during the second period of sexual activity $(\mathrm{F}[8,72]=18 \cdot 8, P<0 \cdot 001)$ (Fig. 2b).

The group receiving cabergoline and protirelin initially demonstrated prolactin levels of more than $20 \mathrm{ng} / \mathrm{ml}$, with a consistent decrease towards upper physiological levels
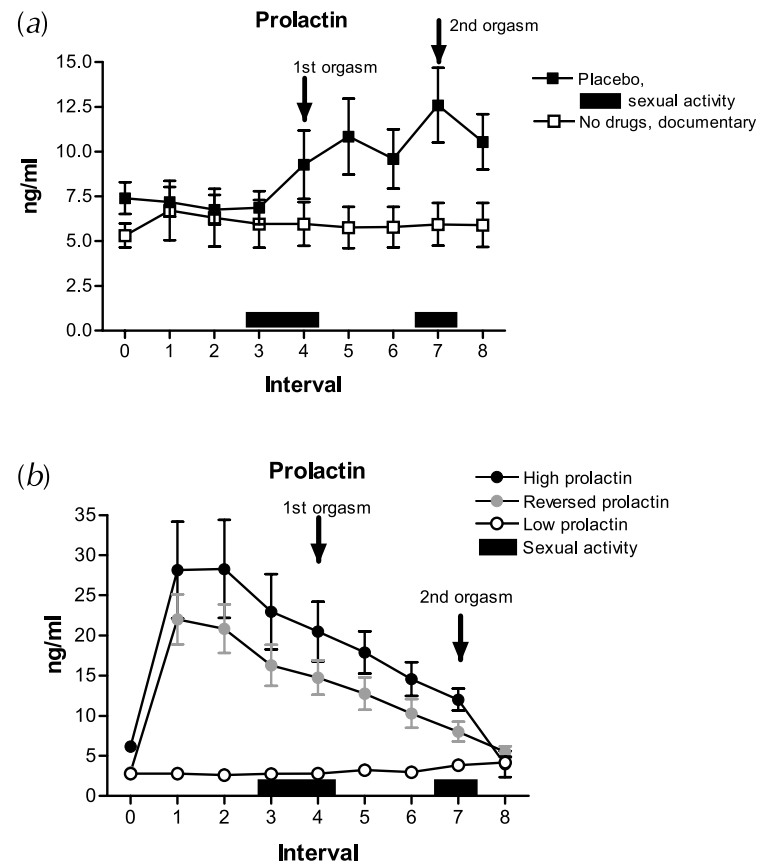

Figure 2 (a) Time course of effects of sexual arousal and orgasm on plasma prolactin levels during the first and second sequence of sexual activity in the group receiving placebo compared with a control condition (documentary). (b) Prolactin plasma levels in the groups with high prolactin (protirelin administration), low prolactin (cabergoline) or reversed prolactin (cabergoline+protirelin). Values are expressed as means \pm S.E.

during the two sequences of sexual activity (mean 16.3 and $8.0 \mathrm{ng} / \mathrm{ml}$ respectively) and a further decline to physiological levels at the end of the examination $(5 \cdot 5 \mathrm{ng} /$ ml) $(\mathrm{F}[8,72]=37 \cdot 18, P<0 \cdot 001)$ (Fig. 2b).

TSH plasma levels were significantly increased when protirelin, or the combination of protirelin and cabergoline was administered $(\mathrm{F}[8,72]=54 \cdot 38, P<0 \cdot 001 ; \mathrm{F}[8,72]=$ $38 \cdot 303, P<0 \cdot 001$ respectively), but were unaffected after placebo or cabergoline administration. Thyroxine and triiodothyronine remained unaltered in all conditions (Table 1).

Plasma concentrations of adrenaline increased significantly, whereas noradrenaline only tended to increase during the two sequences of sexual activity in the placebo condition $(\mathrm{F}[8,72]=3 \cdot 84, \quad P<0 \cdot 01 ; \mathrm{F}[8,72]=1 \cdot 82, \quad P=$ 0.09 respectively), showing no significant differences between the different conditions (Tables 2 and 3). Plasma concentrations of $\mathrm{FSH}, \mathrm{LH}$, testosterone and cortisol were unaltered by sexual activity, with this effect independent of the experimental condition (data not shown).

\section{Subjective sexual functioning}

In the low-prolactin (cabergoline administration) and placebo conditions, all subjects reported having an 
Table 1 Plasma levels of TSH ( $\mu \mathrm{U} / \mathrm{ml}$, means with S.E.) in the different experimental conditions and in the control condition (documentary). Samples $0-8$ represent the different phases of sexual activity as explained in Fig. 1

Sample no.

Low prolactin

High prolactin

Reversed prolactin

Placebo

Control (documentary)

\begin{tabular}{|c|c|c|c|c|c|c|c|c|}
\hline & 1 & 2 & 3 & 4 & 5 & 6 & 7 & 8 \\
\hline $.83(0.08)$ & $0.76(0.07)$ & $0.74(0.08)$ & $0.76(0.08)$ & $0.77(0.08)$ & $0 \cdot 83(0 \cdot 10)$ & $0 \cdot 86(0.06)$ & $0 \cdot 83(0 \cdot 10)$ & $0.91(0.14)$ \\
\hline $1 \cdot 18(0 \cdot 08)$ & $4.46(0 \cdot 48)$ & $5.46(0.54)$ & $5.13(0.53)$ & $4.63(0.43)$ & 4.08 & $3 \cdot 72(0 \cdot 31)$ & $2.95(0.25)$ & $2 \cdot 78(0 \cdot 22)$ \\
\hline $1 \cdot 01(C$ & 3.95 & & $4.89(0 \cdot)$ & & & & $2 \cdot 94(0 \cdot 44)$ & $2 \cdot 69(0 \cdot 38)$ \\
\hline & $1 \cdot 12$ & & & & & & & 17) \\
\hline $0.84(0.09)$ & $0.76(0.07)$ & $0.74(0.08)$ & $0.76(0.08)$ & $0.77(0.09)$ & $0 \cdot 83(0 \cdot 10)$ & $0.86(0.06)$ & $0.83(0 \cdot 10)$ & $0.92(0.14)$ \\
\hline
\end{tabular}

Table 2 Plasma levels of adrenaline (pg/ml, means with S.E.) in the different experimental conditions and in the control condition (documentary). Samples $0-8$ represent the different phases of sexual activity as explained in Fig. 1

\section{Sample no.}

Low prolactin

High prolactin

Reversed prolactin

Placebo

Control (documentary)

\begin{tabular}{|c|c|}
\hline 0 & 1 \\
\hline $43 \cdot 8(9 \cdot 0)$ & $33 \cdot 1(9 \cdot 5)$ \\
\hline $36 \cdot 7(6 \cdot 5)$ & $33 \cdot 1(7 \cdot 4)$ \\
\hline $50 \cdot 7(10 \cdot 6)$ & $59 \cdot 5(10 \cdot 8)$ \\
\hline $41 \cdot 6(7 \cdot 5)$ & $34 \cdot 5(5 \cdot 8)$ \\
\hline $39 \cdot 5(7 \cdot 7)$ & $29 \cdot 2(6 \cdot 0)$ \\
\hline
\end{tabular}

\begin{tabular}{l}
4 \\
\hline $37 \cdot 2(8 \cdot 4)$ \\
$41 \cdot 9(6 \cdot 3)$ \\
$87 \cdot 7(24 \cdot 9)$ \\
$42 \cdot 1(6 \cdot 0)$ \\
$25 \cdot 8(4 \cdot 7)$
\end{tabular}

$\overline{26 \cdot 5(6 \cdot 3)}$

$28 \cdot 5(3 \cdot 8)$

$48 \cdot 4(10 \cdot 1)$

$31 \cdot 0(4 \cdot 5)$

$26 \cdot 5(5 \cdot 0)$

\begin{tabular}{|c|c|c|}
\hline 6 & 7 & 8 \\
\hline $27 \cdot 5(6 \cdot 7)$ & $40 \cdot 7(8 \cdot 8)$ & $37.9(9 \cdot 4)$ \\
\hline $26 \cdot 5(4 \cdot 1)$ & $32 \cdot 6(5 \cdot 5)$ & $37 \cdot 6(6 \cdot 2)$ \\
\hline $46 \cdot 3(10 \cdot 4)$ & $51.6(8.0)$ & $51 \cdot 3(7 \cdot 8)$ \\
\hline $29 \cdot 2(4 \cdot 6)$ & $37 \cdot 3(7 \cdot 3)$ & $38.6(6.7)$ \\
\hline $27 \cdot 7(5 \cdot 8)$ & $37 \cdot 4(6 \cdot 7)$ & $37.5(5.6)$ \\
\hline
\end{tabular}

orgasm during both the first and second sequence of sexual activity. Two participants in the reversed prolactin (cabergoline and protirelin), and one subject in the elevated prolactin (protirelin) condition reported having difficulties in achieving an orgasm during the first or second sequence of sexual activity. Figure 3 displays the ejaculation latency indicated by the subjects. There was a significant difference between the high and reversed prolactin condition compared with placebo during the first sequence $(t[9]=2 \cdot 822$, $P<0.05 ; \quad t[9]=-2.799, \quad P<0.05$ respectively) and between the low-prolactin and high-prolactin conditions during the reinitiation of sexual activity $(t[9]=-2 \cdot 875$, $P<0 \cdot 05)$.

Furthermore, cabergoline-induced hypoprolactinemia significantly enhanced all parameters of sexual drive and function, as measured by the ASES, including appetitive and consummatory sexual behavior during the first $(t[9]=2 \cdot 681, P<0 \cdot 05 ; t[9]=3.383, P<0 \cdot 01$ respectively $)$ and second sequence of sexual activity $(t[9]=2 \cdot 465$, $P<0 \cdot 05 ; t[9]=3 \cdot 498, P<0 \cdot 01$ respectively). Additionally, positive aspects of the refractory period such as sexual release and relaxation were significantly enhanced (positive scale) $(t[9]=3.534, P<0 \cdot 01)$, whereas the negative scale of refractory period did not reveal any differences $(t[9]=0.475, P=0.65)$ (Fig. 3).

However, reversed prolactin plasma concentration after administration of cabergoline in combination with protirelin inverted this effect, with participants showing no alteration of sexual drive and function during the first $(t[9]=1 \cdot 017, P=0 \cdot 34 ; t[9]=1 \cdot 058, P=0 \cdot 32$ respectively) and second sequences of sexual activity $(t[9]=1.565$, $P=0.16 ; t[9]=0.007, P=0.995$ respectively), as well as the refractory period (negative scale: $t[9]=1 \cdot 373, P=0 \cdot 20$; positive scale: $t[9]=1 \cdot 645, P=0 \cdot 14$ ) (Fig. 3).

Increasing prolactin concentrations by administration of protirelin only tended to reduce sexual drive and function during the first $(t[9]=1 \cdot 102, P=0 \cdot 30 ; t[9]=1 \cdot 500, P=0 \cdot 17$

Table 3 Plasma levels of noradrenaline ( $\mathrm{pg} / \mathrm{ml}$, means with S.E.) in the different experimental conditions and in the control condition (documentary). Samples 0-8 represent the different phases of sexual activity as explained in Fig. 1

\begin{tabular}{|c|c|c|c|c|c|c|c|c|c|}
\hline & \multicolumn{9}{|c|}{ Sample no. } \\
\hline High prolactin & $261(29)$ & $243(38)$ & $216(33)$ & $237(31)$ & $301(49)$ & $244(43)$ & $235(33)$ & $371(48)$ & $410(157)$ \\
\hline Reversed prolactin & $337(44)$ & $328(56)$ & $298(50)$ & $369(67)$ & $476(118)$ & $455(108)$ & $310(60)$ & $476(76)$ & $512(80)$ \\
\hline Placebo & $280(50)$ & $235(34)$ & $212(32)$ & $242(30)$ & $290(38)$ & $229(30)$ & $210(30)$ & $342(53)$ & $372(43)$ \\
\hline Control (documentary) & $305(45)$ & $202(28)$ & $209(26)$ & $198(30)$ & $189(30)$ & $190(29)$ & $213(29)$ & $334(44)$ & $392(66)$ \\
\hline
\end{tabular}


Ejaculation Latency
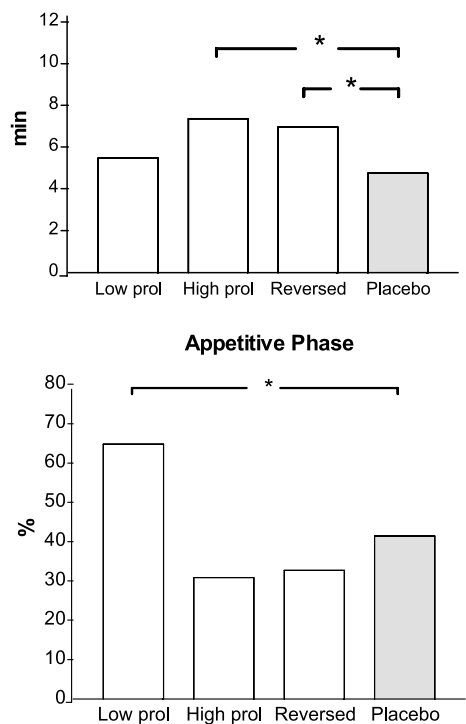

Consummatory Phase

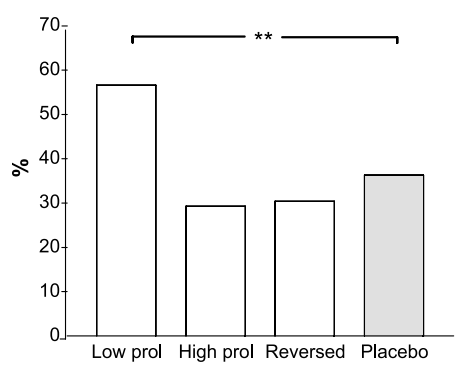

Refractory Phase negative scale

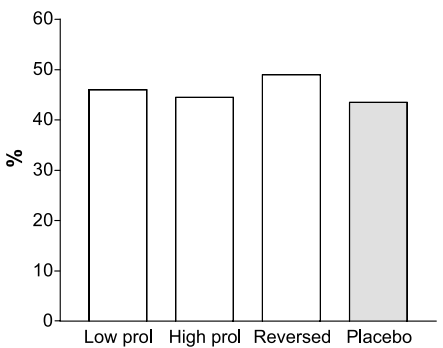

Ejaculation Latency after Reinitiation

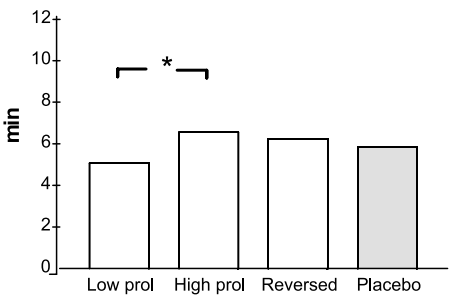

Appetitive Phase after Reinitiation

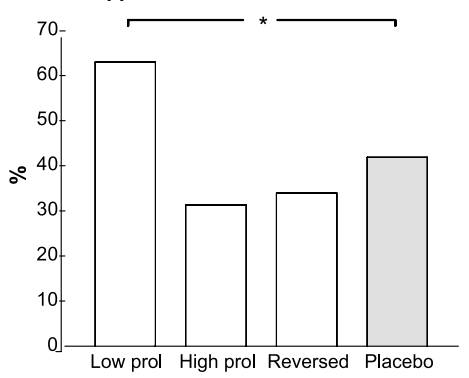

Consummatory Phase after Reinitiation

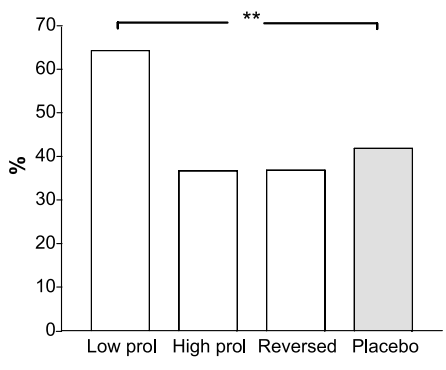

Refractory Phase

positive scale

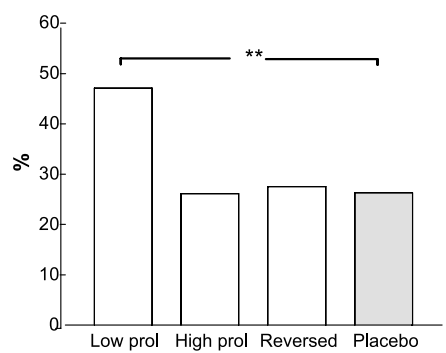

Figure 3 Effects of low prolactin (cabergoline administration), high prolactin (protirelin), reversed prolactin (cabergoline+protirelin) and placebo on ejaculation latency, sexual drive, consummatory sexual experience and refractory period during the first and second (reinitiation) sequence of sexual activity, as measured by the ASES using control items (ejaculation latency) and visual analog rating scales (all other parameters). Except for ejaculation latency (min), questionnaire values represent percent of maximum sexual experience. Values are expressed as means \pm S.E. ${ }^{* *} P<0 \cdot 01 ;{ }^{*} P<0 \cdot 05$.

respectively) and second sequences of sexual activity $(t[9]=1 \cdot 566, P=0 \cdot 15 ; t[9]=0 \cdot 899, P=0 \cdot 40$ respectively $)$

(Fig. 3).

\section{Discussion}

In a series of studies we have consistently demonstrated that prolactin plasma concentrations are substantially 
increased for over $1 \mathrm{~h}$ following orgasm in men and women, but unchanged following sexual arousal without orgasm (Krüger et al. 1998, 2003; M S Exton et al. 1999, 2001a, N G Exton et al. 2000). Therefore, the present investigation aimed to examine the physiological impact of acute alterations of prolactin on sexual parameters by pharmacological manipulation of prolactin levels in healthy men.

This study demonstrates that acute changes in prolactin levels may be one causal factor that modulates acute sexual drive and function after orgasm. Specifically, increasing prolactin concentrations by protirelin administration produced significantly longer ejaculation latency during the first sequence of sexual activity, but only small reductions of sexual drive and function. In contrast, cabergolineinduced hypoprolactinemia significantly enhanced all parameters of sexual drive and function, as measured by the ASES. Further, reversal of prolactin plasma levels by coadministration of cabergoline and protirelin resulted in participants showing no alterations of sexual drive and function in comparison with the placebo condition. These data suggest a tight association between small, acute changes in plasma prolactin and sexual drive and function.

Indeed, we have recently proposed that orgasminduced prolactin release may be a neuroendocrine reflex for maintaining reproductive functions necessary for fertility, conception and pregnancy. Furthermore, we theorized that prolactin may represent a negative feedback mechanism whereby this hormone may modify the activity of dopaminergic neurons in the CNS that are regarded as controlling sexual motivation and function (Krüger et al. 2002). Nevertheless, this hypothesis was based on the knowledge that chronic hyperprolactinemia produces dramatic reductions in sexual motivation and function (Doherty et al. 1986, Yazigi et al. 1997, Cutler 2003). The current study supports the hypothesis, as in addition to high, chronic changes in plasma prolactin observed in hyperprolactinemia $(>100 \mathrm{ng} / \mathrm{ml})$, acute changes in the normal physiological levels of prolactin may also modify sexual motivation and function. However, the current data do not demonstrate a role for prolactin as a simple and direct negative feedback mechanism. For instance, apart from ejaculation latency, protirelin-induced hyperprolactinemia did not lead to the significant reduction of sexual parameters that would be expected in a tight feedback loop. Furthermore, in the placebo condition, the sexual experience of the second sequence, where prolactin levels were already increased, was not different to the first episode. Thus, these data suggest that although prolactin is important in the post-orgasmic regulation of sexual behavior, it is likely to be one signal within a network of psycho-neuroendocrine regulation of acute sexual experience.

As a further caveat, we must note that this study was limited by methodological challenges. The manipulation of prolactin plasma levels in humans was achieved by indirect means, via the administration of prolactin- releasing or -inhibiting drugs. To date, prolactin or prolactin receptor antagonists are unavailable, unaffordable or not safe for use in humans. Consequently, we used the dopamine agonist cabergoline, which reliably decreases prolactin plasma levels. Dopamine agonists have been shown to facilitate not only animal (Hull et al. 1999) but also human sexual behavior (Giuliano \& Allard 2001). However, it seems that the enhancing effects of decreased prolactin levels on sexual drive and function are not exclusively explainable by the direct dopaminergic effects of cabergoline. Indeed, increasing prolactin by coadministration of protirelin completely abrogated the sexual increases observed under single cabergoline administration. Thus, dopaminergic properties of cabergoline may regulate the increase in sexual experience, but this is dependent on prolactin levels.

It is important to note the novel methods of recording physiological and psychological data of the sexual experience. Objective assessment of sexual parameters like penile tumescence or rigidity are not practical in this kind of investigation. Therefore, orgasm was detected online by an increase of cardiovascular activity, followed by a rapid decrease immediately after orgasm; analysis of prolactin concentrations and direct report from the subjects via intercom were also used. The combination of these methodologies allowed accurate registration of ejaculation latency. Moreover, certain aspects of sexual behavior like quality and intensity of orgasm, or characteristics of the refractory period are hardly detectable with objective techniques. To date there is no standardized questionnaire for the assessment of acute sexual experience in such an experimental setting. Consequently, most psychometric sexual data were recorded by the ASES, which remains to be standardized/validated. Nevertheless, the consistency and strength of the relationship between altered prolactin levels and scores in the ASES allow a certain confidence in the demonstrated impact of hormonal alterations on parameters of sexual drive, consummation and refractoriness. Undoubtedly, further studies are needed to further develop this kind of questionnaire for experimental sex research.

In conclusion, these data corroborate the hypothesis that, beside a neuroendocrine reproductive reflex, acute prolactin alterations following orgasm may be one factor modulating acute sexual drive and behavior. However, the study further demonstrates that post-orgasmic increases of prolactin probably do not represent a direct negative feedback mechanism to the CNS but are likely to be one signal among a complex interaction of neuropeptides, monoamines and neurotransmitters controlling sexual behavior (Argiolas 1999, Pfaus 1999, Meston \& Frohlich 2000). Besides the theoretical importance of these data, the effects of cabergoline-induced hypoprolactinemia may have an immense clinical impact for the application of dopamine agonists in the treatment of both disorders of sexual drive. 


\section{Funding}

This study was supported by a grant from the Deutsche Forschungsgemeinschaft (Sche 341/10-1).

\section{References}

Andreotti AC, Pianezzola E, Persiani S, Pacciarini MA, Benedetti MS \& Pontiroli AE 1995 Pharmacokinetics, pharmacodynamics, and tolerability of cabergoline, a prolactin-lowering drug, after administration of increasing oral dose (0.5, 1.0, and 1.5 milligrams) in healthy male volunteers. Journal of Clinical Endocrinology and Metabolism 80 841-845.

Argiolas A 1999 Neuropeptides and sexual behavior. Neuroscience and Biobehavioral Reviews 23 1127-1142.

Bancroft J \& Janssen E 2000 The dual control model of male sexual response: a theoretical approach to psychogenic erectile dysfunction. Neuroscience and Biobehavioral Reviews 24 571-579.

Bole-Feysot C, Goffin V, Edery M, Binart N \& Kelly PA 1998 Prolactin (PRL) and its receptor: actions, signal transduction pathways and phenotypes observed in PRL receptor knockout mice. Endocrine Reviews 19 225-268.

DeMaria JE, Lerant AA \& Freeman ME 1999 Prolactin activates all three populations of hypothalamic neuroendocrine dopaminergic neurons in ovariectomized rats. Brain Research 837 236-241.

Cutler AJ 2003 Sexual dysfunction and antipsychotic treatment. Psychoneuroendocrinology 28 69-82.

Doherty PC, Baum MJ \& Todd RB 1986 Effects of chronic hyperprolactinemia on sexual arousal and erectile function in male rats. Neuroendocrinology 42 368-375.

Ehrenreich H, Schuck J, Stender N, Pilz J, Gefeller O, Schilling L, Poser W \& Kaw S 1997 Endocrine and hemodynamic effects of stress versus systemic CRF in alcoholics during early and medium term abstinence. Alcoholism, Clinical and Experimental Research 21 1285-1293.

Exton MS, Bindert A, Krüger THC, Scheller F, Hartmann U \& Schedlowski M 1999 Cardiovascular and endocrine alterations after masturbation-induced orgasm in women. Psychosomatic Medicine 61 280-289.

Exton MS, Krüger THC, Koch M, Paulson E, Knapp W, Hartmann U \& Schedlowski M 2001a Coitus-induced orgasm stimulates prolactin secretion in healthy subjects. Psychoneuroendocrinology 26 287-294.

Exton MS, Krüger THC, Bursch N, Haake P, Knapp W, Schedlowski M \& Hartmann U $2001 b$ Neuroendocrine response to masturbation-induced orgasm in healthy men following a 3-week sexual abstinence. World Journal of Urology 19 377-382.

Exton NG, Truong TC, Exton MS, Wingenfeld SA, Leygraf N, Saller B, Hartmann U \& Schedlowski M 2000 Neuroendocrine response to film-induced sexual arousal in men and women. Psychoneuroendocrinology 25 187-199.

Gangong WF 2000 Circumventricular organs: definition and role in the regulation of endocrine and autonomic function. Clinical and Experimental Pharmacology and Physiology 27 422-427.

Garbutt JC, Mayo JP, Little KY, Gillette GM, Mason GA, Dew B \& Prange AJ 1994 Dose-response studies with Protirelin. Archives of General Psychiatry 51 875-883.
Giuliano F \& Allard J 2001 Dopamine and sexual function. International Journal of Impotence Research 13 S18-S28.

Goffin V, Binart N, Clement-Lacroix P, Bouchard B, Bole-Feysot C, Edery M, Lucas BK, Touraine P, Pezet A, Maaskant R et al. 1999 From the molecular biology of prolactin and its receptor to the lessons learned from knockout mice models. Genetic Analysis $\mathbf{1 5}$ 189-201.

Horita A 1998 An update on the CNS actions of TRH and its analogs. Life Sciences 62 1443-1448.

Hull EM, Lorraine DS, Du J, Matuszewich L, Lumley LA, Putnam SK \& Moses J 1999 Hormone-neurotransmitter interactions in the control of sexual behavior. Behavioural Brain Research 105 105-116.

Hummer M, Kemmler G, Kurz M, Kurzthaler I, Oberbauer H \& Fleischhacker WW 1999 Sexual disturbance during clozapine and haloperidol treatment for schizophrenia. American Journal of Psychiatry 156 631-633.

Knegtering M, van der Moolen AE, Castelein S, Kluiter H \& van den Bosch RJ 2003 What are the effects of antipsychotics on sexual dysfunctions and endocrine functioning? Psychoneuroendocrinology 28 (Suppl) 109-123.

Krüger THC, Exton MS, Pawlak C, von zur Mühlen A, Hartmann U \& Schedlowski M 1998 Neuroendocrine and cardiovascular response to sexual arousal and orgasm in men. Psychoneuroendocrinology 23 401-411.

Krüger THC, Haake P, Hartmann U, Schedlowski M \& Exton MS 2002 Orgasm-induced prolactin secretion: feedback control of sexual drive? Neuroscience and Biobehavioral Reviews 26 31-44.

Krüger THC, Haake P, Chereath D, Knapp W, Jannsen OE, Exton MS, Schedlowski M \& Hartmann U 2003 Specificity of the neuroendocrine response to orgasm during sexual arousal in men. Journal of Endocrinology 177 57-64.

Macleod RM \& Lehmeyer JE 1974 Studies on the mechanism of the dopamine-mediated inhibition of prolactin secretion. Endocrinology 94 1077-1085.

Meston CM \& Frohlich PF 2000 The neurobiology of sexual function. Archives of General Psychiatry 57 1012-1030.

Outhit A, Morel G \& Kelly PA 1993 Visualization of gene expression of short and long forms of prolactin receptor in the rat reproductive tissues. Biology of Reproduction 49 528-536.

Pfaus JG 1999 Neurobiology of sexual behavior. Current Opinion in Neurobiology 9 751-758.

Smedes F, Kraak JC \& Poppe H 1982 Simple and fast solvent extraction system for selective and quantitative isolation of adrenaline, noradrenaline and dopamine from plasma and urine. Journal of Chromatography 231 25-39.

Sobrinho LG 1993 The psychogenic effects of prolactin. Acta Endocrinologica 129 S38-S40.

Verhelst J, Abs R, Maiter D, van den Bruel A, Vandeweghe M, Velkeniers B, Mockel J, Lamberigts G, Petrossians P, Coremans P et al. 1999 Cabergoline in the treatment of hyperprolactinemia: a study in 455 patients. Journal of Clinical Endocrinology and Metabolism $842518-2522$.

Yazigi RA, Quintero CH \& Salameh WA 1997 Prolactin disorders. Fertility and Sterility 67 215-225.

Received 2 May 2003

Accepted 26 August 2003

Made available online as an

Accepted Preprint on 28 August 2003 